\title{
Pesquisa em Ensino de Física
}

\section{Relação entre o desempenho em física e o desempenho em outras disciplinas da etapa inicial de um curso de engenharia \\ (Relations between academic performance in physics and performance in other areas at the first stage of an engineering course)}

\author{
Fábio Gerab ${ }^{\mathbb{1}}$ Araceli Denise Antunez Valério² \\ ${ }^{1}$ Departamento de Matemática, Centro Universitário da FEI, São Bernardo do Campo, SP, Brasil \\ ${ }^{2}$ Departamento de Engenharia de Produção, Centro Universitário da FEI, São Bernardo do Campo, SP, Brasil \\ Recebido em 7/10/13; Aceito em 22/3/14; Publicado em 6/6/2014
}

\begin{abstract}
Este trabalho estudou os indicadores de desempenho acadêmico na etapa inicial de cursos de engenharia buscando identificar padrões de relação entre o desempenho acadêmico obtido na disciplina de Física I e o rendimento nas demais disciplinas do primeiro semestre deste curso, ministrado tanto no período diurno como no noturno. Utilizou-se Análise por Regressão Linear Múltipla (RLM) e Análise por Regressão Logística (RL). Os desempenhos dos alunos ingressantes tanto no primeiro semestre como no segundo semestre do ano foram analisados separadamente e seus resultados comparados. A consistência entre os resultados obtidos pela RLM e pela RL foi verificada, selecionando-se o melhor modelo preditivo para o desempenho em Física I. Determinaram-se os impactos significativos do desempenho acadêmico nas demais disciplinas no desempenho em Física I. Neste contexto destacou-se a importância dos conhecimentos de cálculo vetorial e geometria analítica como fortemente relacionados com o desempenho em Física I. Como a disciplina Física I é ministrada no primeiro semestre para o curso diurno e no segundo semestre para o curso noturno, investigou-se a existência de ganhos de desempenho associados a este remanejamento da disciplina de Física I no noturno. Para tanto, o modelo de RLM determinado para os alunos do curso diurno foi tomado como referência e aplicado aos alunos do curso noturno. Os resultados obtidos não foram capazes de apontar diferenças no desempenho.
\end{abstract}

Palavras-chave: ensino de engenharia, ensino de física, ensino de matemática, currículo, análise multivariada.

This work studied the indicators of academic performance in the early stage of engineering courses in order to identify patterns of relation between the academic performance obtained in the subjects Physics I and academic performances in other subjects of the first semester of this course, taught both during the day as at night. Multiple Linear Regression Analysis (RLM) and Logistic Regression analysis (RL) were applied. The performances of the students entering both in the first half and in the second half of the year were analyzed separately and their results were compared. The consistency between the results obtained by the RLM and the RL was verified, by selecting the best predictive model for performance in Physics I. The relation between academic performance in distinct subjects and the performance in Physics I was determined. In this context highlighted the importance of the knowledge of vector calculus and analytic geometry as fundamental to the performance in Physics I. As the Physics I subject is offered during the first semester for the daytime course and during the second semester to the night course, this work investigated possible performance gains associated with the relocation of the Physics I subject for the second semester for night course. To this goal, the RLM modem obtained from for the daytime students was taken as a reference and applied to night students. The results obtained were not able to find such performance gains.

Keywords: Engineering education, Physics education, Mathematics education, curriculum, multivariate analysis.

\section{Introdução}

É conhecido que muitos dos alunos ingressantes nos cursos superiores das áreas ditas exatas têm dificuldade na compreensão dos fenômenos físicos. Os alunos que conseguem bons resultados nesta disciplina são vistos como

\footnotetext{
${ }^{1}$ E-mail: prifgerab@fei.edu.br.

uma pequena elite, o que faz pensar que a física seja só para alguns [1]. Apesar de este problema adquirir maiores contornos nos níveis mais básicos de instrução ele também se verifica no ensino superior. O elevado número de reprovações em física e em matemática nos 
vários níveis de ensino e em vários países, comprova a grande dificuldade que os alunos têm na aprendizagem dessa ciência.

A transição do ensino médio para o ensino superior é um grande desafio para os estudantes. Em seu estudo Cunha e Carrilho [2] investigaram o conhecimento das relações entre as primeiras experiências do estudante no ensino superior e o sucesso acadêmico, analisando em que medida as vivências acadêmicas dos alunos ingressantes do primeiro ano de um curso de engenharia militar se apresentam relacionadas com o rendimento acadêmico. Para avaliar as vivências acadêmicas utilizou-se o Questionário de Vivências Acadêmicas (QVA) e para efeitos de avaliação do rendimento escolar dos alunos utilizaram-se três disciplinas que são essenciais à formação do engenheiro, a saber: física, cálculo e álgebra linear. Os resultados sugerem que o rendimento acadêmico pode ser afetado pelas vivências dos estudantes no nível pessoal e de realização acadêmica experimentada no $1^{\circ}$ ano do curso superior.

Os ciclos iniciais de um curso em ciências exatas são os que impõem ao aluno os maiores desafios. Estes desafios, relacionados às dificuldades inerentes ao ingresso no ensino superior, contribuem para a ocorrência de elevados índices de reprovação, principalmente nas disciplinas com conteúdos matemáticos, físicos e computacionais.

Não bastassem as dificuldades adaptativas inerentes ao ingresso no ensino superior, os estudantes de cursos de engenharia muitas vezes se defrontam com dificuldades decorrentes das lacunas do seu conhecimento em matemática e em física deixadas por um ensino médio deficitário. Barbeta e Yamamoto [3] aplicaram um teste adaptado do "Mechanics Baseline Test"(MTB) entre alunos ingressantes no ciclo básico de um curso de engenharia, visando levantar as principais dificuldades conceituais em física no tópico de mecânica clássica. Embora exista uma forte interdependência entre física e matemática e que se observe ao longo dos anos, uma gradual diminuição na capacidade de uso de ferramental matemático por parte dos alunos que ingressam no curso superior, os autores concluíram que não é somente a falta deste ferramental o grande obstáculo para um bom desenvolvimento desses alunos. Os resultados da aplicação do MBT confirmaram a grande deficiência em relação aos conceitos básicos de física. Embora os alunos tenham tido contato prévio com os tópicos explorados pelo teste, o nível de amadurecimento sobre o assunto ainda mostrou-se pequeno, prevalecendo conceitos baseados em um senso comum impreciso. Segundo Freire e Cardoso [4] as concepções trazidas pelos alunos antes da instrução acadêmica, têm limitado suas novas experiências. Associando isto ao ensino convencional de física, os alunos apresentam forte resistência a uma mudança conceitual, aqui entendida como a capacidade que o aluno tem de adquirir novos conceitos ou ampliar conceitos já apreendidos.
Diversos trabalhos têm buscado propostas direcionadas à mitigação destas dificuldades. Segundo Sobrinho e colaboradores [5] ingressantes em cursos de engenharia com sérias deficiências em matemática sofrem influência no rendimento em disciplinas como cálculo diferencial e integral, além de outras disciplinas, como física e química. Esta dificuldade contribui para o aumento da evasão e na retenção de alunos nos cursos de engenharia [6]. Para amenizar esta dificuldade o autor propõe a introdução de um curso rápido de imersão em matemática básica. O estudo já citado, efetuado por Barbeta e Yamamoto [3], revelou que alunos que ingressam em um curso superior de exatas demonstram dificuldades em resolver simples frações, na montagem e resolução de equações, em geometria e em trigonometria, além de possuir grande deficiência em relação aos conceitos básicos de física.

A introdução de componentes curriculares que permitam abordar os temas de matemática e de física através do imbricamento destes conteúdos em atividades práticas foi proposto por Quartieri e colaboradores [7]. Segundo Pietrocola [8], a ciência vale-se da matemática para expressar seu pensamento. Na física, o emprego da matemática torna-se um critério de cientificidade, pois a incapacidade de expressar propriedades de sistemas em linguagem matemática inviabiliza o próprio debate científico. A matemática está hoje alojada de forma definitiva no seio da física servindo de linguagem para esta. Ao colocar a relação entre física e matemática neste patamar, a matemática deixa de ser uma mera ferramenta descritiva para a física e assume a própria expressão do pensamento físico. A matemática, enquanto linguagem, empresta sua própria estruturação ao pensamento científico para compor modelos físicos sobre o mundo. Estas são em última instância, estruturas conceituais que se relacionam ao mundo, mediadas pela experimentação [9].

Ainda segundo Pietrocola, se a matemática é a linguagem que permite ao cientista estruturar seu pensamento para apreender o mundo, o ensino da ciência deve propiciar meios para que os estudantes adquiram esta habilidade. Não parece que o domínio operacional dos conteúdos matemáticos seja capaz de permitir a incorporação de tal habilidade. Não é suficiente conhecer matemática como ferramenta para poder utilizala como estruturante das ideias físicas sobre o mundo [8]. Assim, as dificuldades enfrentadas no ensino das ciências muitas vezes acabam por induzir os professores a procurarem problemas onde eles não existem. Um caso particular disto ocorre quando professores de física acabam por acreditar que seus alunos não aprendem os conteúdos ministrados por insuficiente formação matemática. Segundo o autor, a este tipo de raciocínio subjaz a ideia de que a física se vale da matemática enquanto instrumento para enunciar suas leis e princípios. Seu trabalho busca mostrar que existe uma relação muito mais complexa entre ambas as disciplinas, que 
faz da matemática estruturante do conhecimento físico. Esta relação possui profundas implicações para o ensino de física. Entretanto parece existir uma escassez de pesquisas focadas na compreensão das relações entre a matemática e a física [10].

Karam e Pietrocola [10] discutem a relação existente entre a matemática e a física argumentando que ambas estão profundamente relacionadas desde a essência do conhecimento científico e essa influência mútua tem desempenhado um papel fundamental para o desenvolvimento de ambas, onde casos históricos evidenciam que problemas físicos são motivadores da criação de objetos matemáticos e que conceitos abstratos são comumente interpretados fisicamente. Segundo os autores, quando se refere às teorias da física moderna e contemporânea parece não mais haver sentido em se falar do papel da matemática na física, tal a relação de impregnação entre elas e que a física não se resume a matemática, porém, atualmente parece não existir sem ela. Argumentam, porém que essas duas disciplinas têm sido trabalhadas de maneira independente no contexto do ensino e que os estudantes dificilmente se dão conta dessa crescente relação.

Várias têm sido as iniciativas no sentido de aproximar os ensinos da física e da matemática, tanto no ensino médio como no ensino superior. A utilização da modelagem matemática aplicada ao ensino aprendizagem de física foi avaliada por distintos autores [11-13].

Em sua dissertação Willis [14] aponta para uma abordagem interdisciplinar e contextualizada para o ensino conjunto de física e matemática, buscando contribuir para a solução da questão onde a falta dos conhecimentos matemáticos influenciam na não compreensão adequada de conceitos apresentados na disciplina de física no ensino médio. O autor aponta também que não é possível fazer interdisciplinaridade sem que nela esteja contida a contextualização.

Em seu trabalho Galo e Macedo [15] propõem um currículo mínimo de formação básica geral unificada para todas as modalidades de engenharia. Neste currículo, componentes curriculares tais como física, matemática, química, etc. não devem estar isoladas em relação às demais, de forma que os conceitos científicos e tecnológicos devam ser transmitidos com a sua interdisciplinaridade característica de cada assunto, buscando facilitar ao aluno uma visão crítica do objeto de estudo. Em outro trabalho Salvador e colaboradores [16] buscando também uma abordagem interdisciplinar, aplicaram em cursos de engenharia a integração das componentes curriculares Física 1 e Cálculo Diferencial e Integral 1 onde professores de ambas as disciplinas participavam simultaneamente das aulas das duas disciplinas. Os autores reportam não somente o aumento do interesse dos estudantes por estes conteúdos, mas também o aumento da correlação entre as notas obtidas em Física e Cálculo, e tomam isso como evidência de que os estudantes conseguiram efetivamente sentir a integração proposta entre as disciplinas.

Assim, percebe-se que as discussões sobre o aprendizado de física e sua relação com o aprendizado de matemática, apresentam elevada complexidade conceitual, não havendo ainda uma corrente hegemônica na área. Entretanto torna-se clara a ideia que, embora exista uma relação muito próxima entre conteúdos de matemática e física, o conhecimento do primeiro não é condição suficiente para o entendimento do segundo.

\section{Objetivos}

Buscando uma maior reflexão sobre as questões acima expostas, o presente trabalho tem por objetivos:

- Caracterizar as interações curriculares entre as disciplinas do primeiro ciclo de um curso de Engenharia, mensurando o relacionamento entre as disciplinas através de um modelo linear para o desempenho acadêmico dos alunos ingressantes na disciplina de Física I e o desempenho acadêmico nas demais disciplinas do primeiro ciclo do curso.

- Identificar, dentro do modelo proposto, a importância relativa das disciplinas oferecidas no primeiro ciclo para o desempenho em Física I.

- Investigar possíveis ganhos de desempenho em Física I, para o curso noturno, associados ao remanejamento da disciplina de Física I do primeiro para o para o segundo ciclo do curso.

\section{Justificativa}

O conhecimento matemático coloca-se muitas vezes como algo preliminar à aprendizagem da física, entretanto, como discutido anteriormente, não se trata apenas de saber matemática para poder compreender os conceitos tratados nas disciplinas de física, mas também de saber aprender teoricamente a representação do comportamento da natureza através de uma estruturação matemática [8].

Assim, estudar a relação entre os conteúdos tipicamente abordados no primeiro ciclo de um curso de engenharia, através do desempenho dos estudantes, tendo o foco principal na disciplina inicial de física, permite uma melhor compreensão das dificuldades do ingressante quando confrontado com este novo conteúdo. A melhor compreensão destas relações traz subsídios para o desenvolvimento de estratégias pedagógicas que busquem um melhor desempenho dos estudantes em física nestas etapas iniciais de seu curso.

\section{Materiais e Métodos}

\subsection{Os cursos de engenharia estudados}

Os cursos de engenharia estudados, assim como muitos outros cursos de graduação, apresenta uma or- 
ganização curricular de base disciplinar. Esta estrutura, embora seja tanto cômoda como útil, ao conceder uma ordem lógica e linear aos conteúdos curriculares, pode apresentar-se como facilitadora da fragmentação do conhecimento e estimuladora da especialização de funções [17].

Identificar e mensurar as interdependências entre os conteúdos apresentados em diferentes disciplinas do curso, através da análise conjunta dos indicadores de desempenho acadêmico, permite também investigar o grau de integração ou de fragmentação destes conteúdos percebido pelo aluno durante seu processo de aprendizagem.

Os cursos de engenharia na instituição estudada são ministrados tanto no período diurno como no noturno, com duração de 10 e 12 semestres respectivamente. Es- tes cursos são compostos por um bloco comum de disciplinas, constituído pelos dois primeiros semestres do curso diurno e pelos três primeiros semestres do curso noturno. Estes cursos tem para o período diurno seu primeiro semestre constituído por sete disciplinas descritas abaixo, a saber: Cálculo Diferencial e Integral I, Cálculo Vetorial e Geometria Analítica, Introdução a Computação, Desenho Técnico, Sociologia, Física I e Educação Física. Para os cursos de engenharia ministrados no período noturno, a disciplina Física I foi deslocada para o $2^{\circ}$ semestre e disciplina Educação Física foi suprimida. As ementas, cargas horárias e nomenclaturas destas disciplinas são apresentadas na Tabela 1. Os códigos das disciplinas iniciados com $\mathrm{N}$ referem-se às disciplinas ministradas no período noturno, as demais são ministradas nos cursos diurnos.

Tabela 1 - Disciplinas iniciais dos cursos de Engenharia.

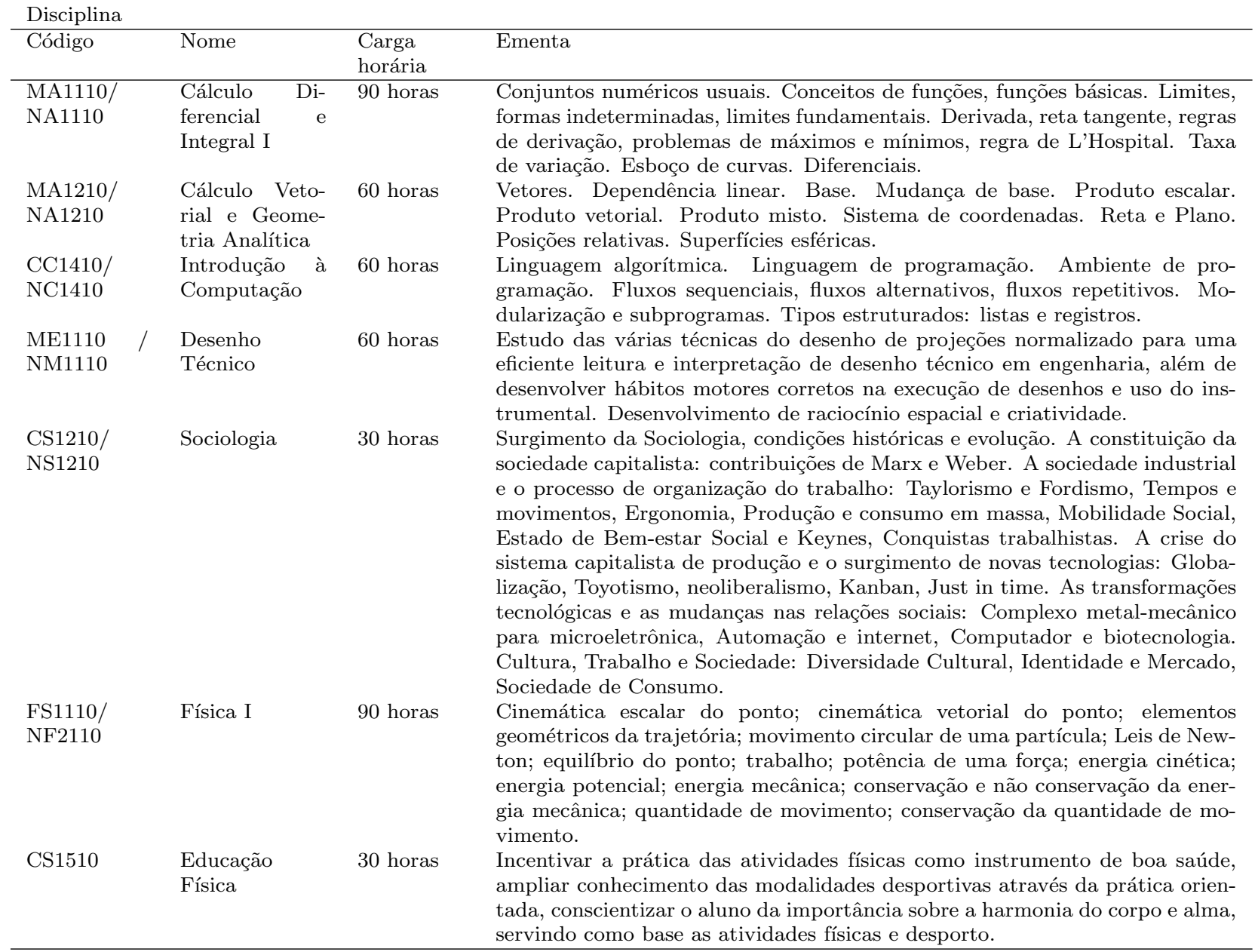

\subsection{Metodologia}

Inicialmente buscou-se na base de dados da Instituição o conjunto das notas dos alunos ingressantes nos cursos de Engenharia, diurno e noturno, durante o ano de 2011, tanto através do processo seletivo de janeiro como no de julho. Tomando um modelo onde se busca descrever o desempenho na disciplina Física I a partir do desempenho nas demais disciplinas do primeiro se- 
mestre, dois modelos preditivos foram construídos. O primeiro foi um modelo linear, utilizando Regressão Linear Múltipla (RLM). O segundo um modelo não linear, utilizando Regressão Logística (RL) [18]. Em princípio, todas as disciplinas do primeiro semestre podem apresentar uma contribuição relevante para o desempenho em Física 1, pois o ferramental matemático básico é revisitado e expandido em Cálculo Diferencial e Integral I, a noção de vetores é desenvolvida em Cálculo Vetorial e Geometria Analítica, o raciocínio lógico é trabalhado em Introdução a Computação, a visão espacial é desenvolvida em Desenho Técnico e a interpretação correta de enunciados poderia, em princípio, ser facilitada pela disciplina de Sociologia que exige leitura e compreensão de textos. Educação Física não foi incluída na análise, pois ela só é ministrada para os cursos diurnos.

$\mathrm{Na}$ RLM busca-se descrever o comportamento de uma única variável métrica predita (desempenho em Física I) por uma combinação linear, estatisticamente significativa, de várias variáveis preditoras (desempenho nas demais disciplinas do primeiro ciclo). Na Regressão Linear Múltipla o grau de associação e a qualidade do ajuste linear da variável predita por um conjunto de outras variáveis é avaliada pelo coeficiente de determinação múltiplo ajustado $\mathrm{R}_{\text {ajust }}^{2}$. A importância relativa de cada disciplina na explicação do desempenho em Física I é fornecida pelos coeficientes lineares reduzidos ( $\beta$ 's reduzidos).

No modelo de RL busca-se, através de uma regressão não linear, explicar a ocorrência de fenômenos descritos por uma variável de natureza binária. A RL é uma técnica estatística utilizada para descrever a relação de uma variável predita binária com variáveis independentes métricas ou não métricas, ou seja, destina-se a investigar o efeito das variáveis pelas quais os indivíduos, objetos ou sujeitos estão expostos sobre a probabilidade de ocorrência do evento de interesse [19]. A vantagem da regressão logística diante de outras técnicas está na flexibilidade de seus cálculos, ampliando assim sua aplicabilidade. Constata-se que a RL difere da RLM, pois não pressupõe normalidades dos resíduos [19]. A regressão logística também não pressupõe homogeneidade de variância assim, a redução do número de pressupostos torna-a preferível em muitas situações práticas. Todas as análises estatísticas foram realizadas com o auxílio do software Statistical Package for Social Sciences - IBM SPSS Statistics Version 19 release 19.0.0. Para todos os modelos utilizou-se um nível de significância de 0,05 .

Inicialmente analisaram-se os resultados de desempenho referentes aos alunos ingressantes em 2011 no curso de engenharia diurno. As análises estatísticas foram realizadas em separado para os ingressantes no início do ano e no meio do ano. Este cuidado deveu-se a suposição de existência de diferenças sistemáticas entre os desempenhos dos alunos ingressantes no curso nos processos seletivos de janeiro e julho. Ambas às análises de regressão, RLM e RL, foram aplicadas. Para a RLM tomou-se como variável predita a nota obtida em Física I. Já para a RL utilizou-se como variável predita binária a aprovação nesta disciplina, de maneira que a variável assumiu o valor um em caso de aprovação e zero em caso de reprovação em Física I. A partir dos resultados obtidos selecionou-se o modelo de previsão (RLM ou RL) mais adequado. Como veremos adiante, o modelo de RLM foi o selecionado para as demais etapas da análise. A partir do modelo de RLM foi possível determinar a importância relativa do desempenho nas distintas disciplinas do primeiro ciclo do curso para o desempenho em Física I.

$\mathrm{Na}$ etapa seguinte, utilizando os coeficientes lineares do modelo de RLM desenvolvido a partir das notas dos alunos do curso diurno e tomando como variáveis preditoras as notas obtidas nas disciplinas do primeiro ciclo cursadas pelos alunos do curso noturno ingressantes em 2011, simulou-se a nota esperada em Física I para estes alunos do noturno como se esta disciplina tivesse sido cursada no primeiro semestre do curso e não no segundo. A partir da comparação entre a nota simulada e a nota realmente obtida em Física I pelos alunos do curso noturno, buscaram-se evidências de algum ganho no desempenho dos alunos do noturno nesta disciplina devido ao fato de Física I ter sido deslocada para o segundo semestre nos cursos noturnos.

A aplicação do modelo foi feita para todos os alunos do noturno, contudo, para um melhor entendimento dos resultados, realizaram-se também análises estratificando os alunos em três grupos: alunos sem disciplinas do semestre anterior cursadas em regime de dependência (DP), alunos com uma dependência e alunos com duas dependências. É importante ressaltar que os alunos do noturno incorporados à análise foram somente àqueles que progrediram para o segundo semestre do curso de Engenharia, pois a disciplina de Física I é ministrada no segundo semestre para o período do noturno. Como um dos critérios de progressão de semestre é não ter mais do que duas disciplinas de semestres anteriores em regime de dependência, o numero de alunos estudados do noturno foi consideravelmente reduzido. Buscou-se também, para os alunos do noturno, utilizando o modelo de RLM, identificar a importância relativa do desempenho nas demais disciplinas do primeiro ciclo no rendimento em Física I.

\section{Resultados}

\subsection{Resultados para os alunos do curso diurno}

Para o curso diurno foram analisados os desempenhos de 759 estudantes. Os modelos de regressão RLM e RL foram capazes de obter boas previsões das aprovações ou reprovações em Física I dos alunos do curso diurno. Para o Modelo de RLM a estimativa de uma nota igual ou superior a 5,0 foi tomada como uma previsão de 
aprovação. A Tabela 2 apresenta a síntese dos resultados obtidos para os ingressantes em janeiro de 2011 do curso diurno, tanto para o modelo de RLM como para o de RL.

De acordo com a Tabela 2, observa-se que os modelos finais de regressão não incluíram a disciplina Sociologia (CS1210), pois seus coeficientes, oriundos dos cálculos de regressão, não foram, a um nível de 0,05 , estatisticamente significativos.

O modelo de Regressão Linear Múltipla alcançou $83,8 \%$ de acertos totais. Este modelo mostrou que a disciplina Cálculo Vetorial e Geometria Analítica (MA1210) foi a que apresentou o maior impacto para o desempenho em Física I. Já o menor impacto, ainda que significativo, foi o da disciplina Desenho Técnico. Em relação à multicolinearidade, o VIF (Fator de Inflação da Variância) foi inferior a dez, corroborando para a consistência do modelo de Regressão Linear Múltipla encontrado [18]. Já a Regressão Logística apresentou aproximadamente $90 \%$ de acertos totais. Observou-se que para o modelo de Regressão Logística a disciplina MA1210 também foi a de maior influência para Física I e a disciplina ME1110 continuou sendo a de menor influência.

A Tabela 3 mostra os resultados de regressão para os ingressantes no curso diurno em julho de 2011. Foram analisados os desempenhos de 245 estudantes. Para este grupo de alunos a contribuição da disciplina Sociologia na explicação do desempenho em Física I foi, no modelo de Regressão Linear Múltipla, estatisticamente significativa. O modelo de RLM obteve $89,1 \%$ de acertos totais.

O modelo mostrou que a disciplina MA1210 permaneceu sendo a disciplina mais importante para explicar o desempenho de Física I. Novamente os valores do fator de inflação da variância, VIF, foram pequenos, indicando que o modelo não foi afetado pela existência de fortes multicolinearidades. O modelo de Regressão Logística também obteve $89,1 \%$ de acertos totais. Entretanto, nota-se que para este modelo apenas as disciplinas Cálculo Diferencial e Integral I (MA1110) e Cálculo Vetorial e Geometria Analítica (MA1210) foram estatisticamente significativas, sendo a disciplina MA1210 aquela de maior importância para explicar o desempenho em Física I. Como MA1110 e MA1210 são fortemente correlacionadas, embora não seja fácil dimensionar efeitos de multicolinearidade para a Regressão Logística, estes efeitos podem estar afetando o modelo logístico obtido.

Tabela 2 - Previsão de aprovação em Física I: alunos do diurno ingressantes no processo seletivo de janeiro de 2011 ( $\alpha=0,05$, modelo Backward Stepwise).

\begin{tabular}{|c|c|c|}
\hline Modelo & $\begin{array}{ll}\% \text { de acertos para } & \% \text { de acertos para } \% \text { acertos totais } \\
\text { alunos reprovados } & \text { alunos aprovados }\end{array}$ & Qualidade do ajuste \\
\hline \multirow[t]{2}{*}{ RLM } & $\begin{array}{lll}89,5 & 81,9 & 83,8\end{array}$ & $\mathrm{R}^{2}$ ajustado $=0,773$ \\
\hline & $\begin{array}{l}\mathrm{FS} 1110=1,766+0,156 \mathrm{MA} 1110+0,306 \mathrm{MA} 1210+0,177 \\
\mathrm{CC} 1410+0,113 \mathrm{ME} 1110 \\
\text { Betas reduzidos: } \beta_{1}(\mathrm{MA} 1110)=0,204 ; \beta_{2}(\mathrm{MA} 1210)=0,409 ; \\
\beta_{3}(\mathrm{CC} 1410)=0,173 ; \beta_{4}(\mathrm{ME} 1110)=0,120 \\
\text { Multicolinearidade }\end{array}$ & Máximo VIF = 3,280 \\
\hline \multirow[t]{2}{*}{$\mathrm{RL}$} & $\begin{array}{rl}94,4 & 90,1\end{array}$ & Nagelkerke $\mathrm{R}^{2}=0,779$ \\
\hline & $\begin{array}{l}\beta 0=-4,694 ; \beta 1(\mathrm{MA} 1110)=0,311 ; \beta 2(\mathrm{MA} 1210)= \\
0,590 ; \beta 3(\mathrm{CC} 1410)=0,321 ; \beta 4(\mathrm{ME} 1110)=0,222 \\
\text { Multicolinearidade } \\
\text { Difícil de dime }\end{array}$ & \\
\hline
\end{tabular}

Tabela 3 - Previsão de aprovação em Física I: alunos do diurno ingressantes no processo seletivo de julho de 2011 ( $\alpha=0,05$, modelo Backward Stepwise).

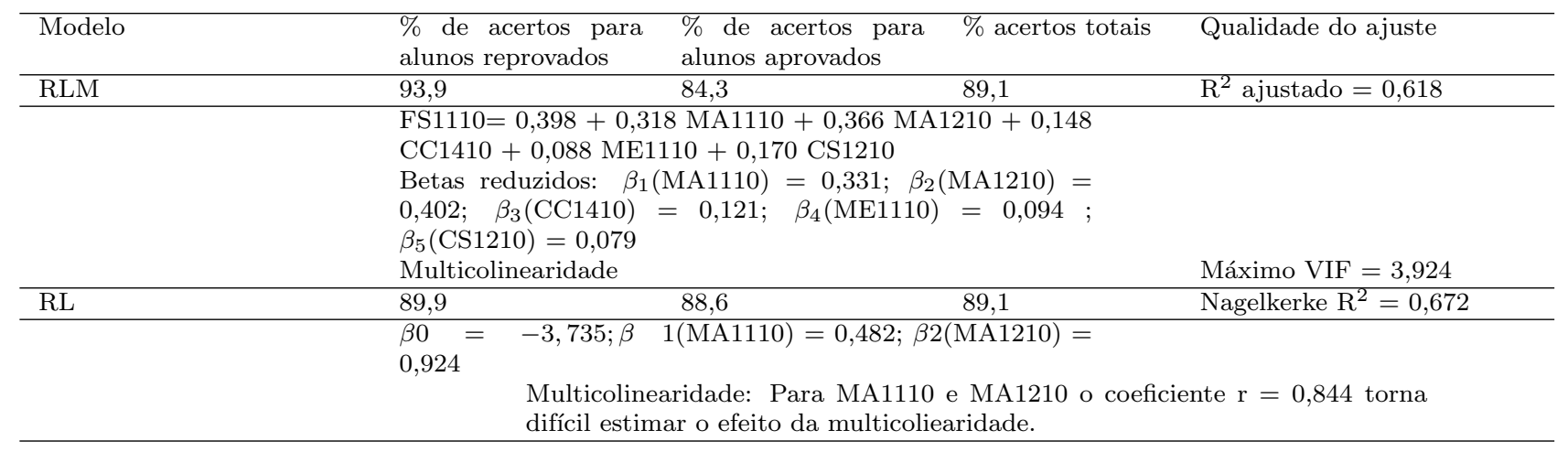


A partir da análise dos resultados obtidos pelos dois modelos de regressão percebe-se que ambos apresentaram capacidades preditivas de aprovação ou reprovação semelhantes. Entretanto, definiu-se que Regressão Linear Múltipla foi mais adequada para utilização na próxima etapa do trabalho. Esta escolha deveu-se ao fato de a RLM modelar não somente a aprovação ou reprovação, mas também determinar um valor para a nota de Física I esperada para o aluno. Além disso, efeitos de multicolinearidade são mais facilmente detectáveis na Regressão Linear Múltipla, quando comparada à Regressão Logística.

\subsection{Resultados para os alunos do curso no- turno}

Ao aplicar o modelo de RLM do diurno para os estudantes do noturno buscou-se estimar suas notas em Física I, simulando a condição de sua hipotética alocação no primeiro semestre do noturno. Pôde-se então estimar as diferenças médias entre as notas estimadas e as notas efetivamente obtidas em Física I quando cursadas pelos alunos do noturno no segundo semestre do curso. Nesta comparação tomou-se o cuidado de distinguir os alunos ingressantes no processo seletivo de janeiro dos ingressantes no processo de julho. Os valores de $\Delta$, referentes média das diferenças obtidas subtraindo-se as notas estimadas das notas obtidas em Física I, são mostrados na Tabela 4 . Valores positivos de $\Delta$ seriam indicativos de um ganho de desempenho em Física I, associado ao fato de esta disciplina ser oferecida no segundo semestre para alunos do curso noturno.

Tabela $4-\Delta$ 's $(\Delta=$ nota de NF2110 real - nota de NF2110 estimado). $\mathrm{DP}=$ dependência de alguma disciplina cursada no ciclo anterior.

\begin{tabular}{lcc}
\hline & \multicolumn{2}{c}{ Processo seletivo } \\
\cline { 2 - 3 } Todos os alunos & Janeiro & Julho \\
Alunos sem DP & $-1,36$ & $-1,74$ \\
Alunos com uma DP & 0,05 & $-1,56$ \\
Alunos com duas DP's & 1,71 & $-1,85$ \\
\hline
\end{tabular}

Constatou-se que não ocorreu ganho de desempenho para os alunos do noturno devido à realocação da disciplina de Física I para o $2^{\circ}$ semestre do curso. Isto se verifica principalmente para os alunos que ingressaram processo seletivo de julho 2011, onde as notas estimadas de NF2110 foram maiores do que as notas realmente obtidas.

Com o propósito de ampliar os estudos sobre a relação entre o desempenho em Física I e as demais disciplinas do primeiro semestre para os alunos do curso noturno, efetuaram-se os modelos de RLM (alunos ingressantes em janeiro e em julho), tanto para todos os alunos como também para os três grupos citados anteriormente. A Tabela 5 apresenta o conjunto dos modelos de RLM obtidos.

De acordo com a Tabela 5, as disciplinas que foram significativas, para os ingressantes em janeiro foram NA1110 e NA1210. No entanto para alunos com uma dependência, NS1210 foi também significativa para o modelo, diferentemente das outras equações onde NA1110 aparece no lugar de NS1210. Os resultados referentes aos ingressantes em julho diferenciam-se dos de janeiro principalmente pela não existência dos modelos significativos de RLM para os alunos com uma e duas dependências.

O conjunto de disciplinas significativas para a explicação das notas de Física I dos ingressantes em julho mostrou-se também distinto das dos ingressantes em janeiro. Tais resultados foram influenciados pelo pequeno número de alunos nestes grupos, como mostra a Tabela 6 , pois, ao se estudar os alunos do noturno, foi necessário retirar da análise grande parte deles, avaliando somente os alunos que obtiveram êxito no primeiro semestre, já que a disciplina de Física I é ministrada no segundo semestre. Quando os $\beta$ 's reduzidos são analisados o modelo de RLM referente a janeiro aponta a disciplina NA1210 como a de maior importância em todos os grupos estudados (todos os alunos, zero, uma e duas dependências). Já para os alunos que ingressaram em julho, tanto no modelo para todos os alunos como para os alunos sem dependências, a variável de maior peso foi NA1110.

Em comparação com os alunos do diurno, foram poucos os alunos do noturno estudados, e os que foram considerados na análise foram aqueles, em princípio, de maior desempenho, uma vez que foram aprovados no primeiro semestre. A Tabela 6 apresenta também os coeficientes de determinação múltiplos, referentes a cada modelo.

Tabela 5 - Modelos de RLM para o período noturno.

\begin{tabular}{|c|c|c|}
\hline $\begin{array}{l}\text { Processo Sele- } \\
\text { tivo }\end{array}$ & Grupo & Modelo de RLM estatisticamente significativo \\
\hline \multirow{4}{*}{ Janeiro } & Todos os alunos & $\mathrm{NF} 2110=1,778+0,357^{*} \mathrm{NA} 1110+0,509 * \mathrm{NA} 1210$ \\
\hline & Alunos sem DP & $\mathrm{NF} 2110=2,911+0,369 * \mathrm{NA} 1110+0,350 * \mathrm{NA} 1210$ \\
\hline & Alunos com $1 \mathrm{DP}$ & $\mathrm{NF} 2110=1,142+0,386^{*} \mathrm{NA} 1210+0,430 * \mathrm{NS} 1210$ \\
\hline & Alunos com 2 DP's & $\mathrm{NF} 2110=1,657+0,343 * \mathrm{NA} 1110+0,536 * \mathrm{NA} 1210$ \\
\hline \multirow{2}{*}{ Julho } & Todos os alunos & $\mathrm{NF} 2110=0,104+0,537^{*} \mathrm{NA} 1110+0,310^{*} \mathrm{NM} 1110$ \\
\hline & Alunos sem DP & $\mathrm{NF} 2110=-0,646+0,553 * \mathrm{NA} 1110+0,404 * \mathrm{NC} 1410$ \\
\hline
\end{tabular}


Tabela 6 - Quantidade de alunos do noturno utilizados para o cálculo do modelo de $\mathrm{RLM}_{\text {e }}$ respectivo $\mathrm{R}^{2}$ ajustado (*Modelo não significativo).

\begin{tabular}{|c|c|c|c|c|c|}
\hline \multicolumn{6}{|c|}{ Processo seletivo } \\
\hline \multicolumn{3}{|c|}{ Janeiro } & \multicolumn{3}{|c|}{ Julho } \\
\hline Condição do aluno & $\mathrm{N}^{\circ}$ de alunos & $\mathrm{R}^{2}$ ajustado & Condição do aluno & $\mathrm{N}^{\circ}$ de alunos & $\mathrm{R}^{2}$ ajustado \\
\hline Todos & 207 & 0,604 & Todos & 71 alunos & 0,510 \\
\hline $0 \mathrm{DP}$ & 85 & 0,327 & $0 \mathrm{DP}$ & 29 alunos & 0,436 \\
\hline $1 \mathrm{DP}$ & 48 & 0,219 & $1 \mathrm{DP}^{*}$ & 16 alunos & - \\
\hline 2 DP's & 71 & 0,295 & $2 \mathrm{DP}^{\prime} \mathrm{s}^{*}$ & 26 alunos & - \\
\hline
\end{tabular}

\section{Considerações finais}

De acordo com os resultados obtidos, a metodologia adotada para a modelagem de desempenho em Física I mostrou-se viável e consistente. Apesar de ambos os modelos de regressão empregados terem apresentado capacidades de previsão semelhantes, o modelo de RLM foi considerado mais adequado por permitir, além de um melhor controle dos efeitos da multicolinearidade, estimar a nota esperada para Física I.

Os resultados apontam que, mesmo em um curso de natureza disciplinar como o estudado, sobrevive uma forte relação entre os distintos conteúdos abordados na etapa inicial de um curso de engenharia. Os modelos de RLM explicaram, para o conjunto dos estudantes, uma fração considerável da variabilidade das notas de Física I. Esta explicação variou de 51\%, para os alunos do noturno ingressantes em julho, a 77\%, para os alunos do diurno ingressantes em janeiro.

Embora várias disciplinas tenham se mostrado significativas para a explicação do desempenho em Física I, percebe-se que, tanto no curso diurno como no curso noturno, as disciplinas com maior relação com o desempenho em Física I foram Cálculo Diferencial e Integral I e Cálculo Vetorial e Geometria Analítica, esta última sempre tendo a maior importância para este desempenho. Tal fato reforça a forte conexão entre os conceitos matemáticos de vetor e suas propriedades e a sua correta aplicação para o entendimento dos conceitos físicos envolvidos no estudo da cinemática e da dinâmica, abordados em Física I.

A comparação entre as notas previstas pelo modelo e obtidas em Física I pelos alunos do curso noturno não evidenciou nenhum ganho de desempenho pelo fato de esta disciplina ter sido deslocada para o segundo semestre. O tamanho reduzido da amostra pode ter influenciado este resultado. Compreende-se também que o perfil dos alunos do noturno é distinto dos alunos do diurno, o que pode também influenciar no comportamento de suas notas.

O conjunto dos resultados, obtidos utilizando-se uma nova abordagem, onde a estatística multivariada foi aplicada à análise do desempenho acadêmico de um conjunto grande de estudantes ingressantes em cursos de engenharia, corrobora a ideia da existência de uma relação complexa entre os conteúdos de física e de ma- temática, conforme discutido por Pietrocola e outros [3,5-10]. A relação significativa encontrada entre os desempenhos nestes conteúdos pode indicar possíveis ganhos para os estudantes, quando da apresentação de forma mais integrada dos conteúdos de física e de matemática, integração esta já defendida por diversos autores [11-16].

\section{Agradecimentos}

Os autores agradecem ao Centro Universitário da FEI pelo suporte financeiro ao trabalho através do programa PBIC.

\section{Referências}

[1] C. Fiolhais, in: Anais do $1^{\circ}$ Colóquio de Física do Instituto Politécnico de Tomar (Coimbra, 2002), p. 195-202. Disponível em http://nautilus.fis.uc.pt/softc/Read_c/RV/ virtual water/articles/art3/art3.htm] (acesso em 26/05/2014).

[2] S.M. Cunha e D.M. Carrilho, Revista Psicologia Escolar e Educacional 9, 215-224 (2005).

[3] V.B. Barbeta e I. Yamamoto, Revista Brasileira de Ensino de Física 24, 324-341 (2002).

[4] P.T.C Freire e H.B. Cardoso, in: Anais do VIII Encontro de Pesquisa em Ensino de Física (Aguas de Lindoia, 2002), p. P028. Disponível em http://wWw.cienciamao.usp.br/dados/epef/ conceltosdef1sicabasicae.trabalho.pdt (acesso em 26/05/2014)

[5] J.C. Sobrinho, E.C. Dechechi e M.M.Detoni, in: Anais COBENGE-2005 (Campina Grande, 2005). Disponível em http://www.abenge.org.br/CobengeAnteriores/ 2005/artigos/PR-5-43002897949-1118675861553. pdf (acesso em 26/05/2014)

[6] V.F. Oliveira, Z. Chamberlain, A. Peres, P.R. Brandt e S.L. Schwertl (orgs), in: Desafios da Educação em Engenharia: Vocação, Formação, Exercício Profissional, Experiências Metodológicas e Proposições (Brasília/Blumenau, ABERGE/EdiFURB, 2012), p. 165-205.

[7] M.T. Quartieri, E.F. Borragini e A.P. Dick, in: Anais COBENGE-2012 (Belém, 2012). Disponível em http://www.abenge.org.br/CobengeAnteriores/ 2012/artigos/103697.pdf (acesso em 26/05/2014) 
[8] M.A. Pietrocola, Caderno Brasileiro do Ensino de Física 19, 88-108 (2002).

[9] M. Bunge, Teoria e Realidade (Perspectiva, São Paulo, 1974).

[10] R. Karam, M. Pietrocola, in: Anais do VII Enpec: Encontro Nacional de Pesquisas em Educação em Ciências (Florianópolis, 2009). Disponível em http://axpfep1.if.usp.br profis/arquivos/ Viienpec/VII\%20ENPEC\%20-\%202009/www.foco.fae. ufmg.br/cd/pdfs/1529.pdf (acesso em 26/05/2014)

[11] C.O. Lozada, M.S.T. Araújo, W. Morrone e L.H. Amaral, Revista LOGOS 149, p. 2-12 (2006).

[12] E.S.R Souza e A.O.E. Santo, in: Anais do IV Encontro Paraense em Educação Matemática (Belém, 2008). Disponível em http://www.educadores. diaadia.pr.gov.br/arquivos/File/2010/artigos teses/fisica/artigos/ednilson.pdf (acesso em 26/05/2014)

[13] L.S. Campos e M.S.T. Araújo, in: Anais do VII Enpec: Encontro Nacional de Pesquisas em Educação em Ciências (Florianópolis, 2009). Disponível em http://posgrad.fae.ufmg.br/posgrad/ viienpec/pdfs/1753.pdf (acesso em 26/05/2014)
[14] S.L.N. Willis, O Ensino Interdisciplinar entre Física e Matemática: Uma Nova Estratégia para Minimizar o Problema da Falta de Conhecimentos Matemáticos no Desenvolvimento do Ensino de Física. Dissertação, UNIGRANRIO, 2011.

[15] J.J.M. Galo e M.N.Q.M. Macedo, in: Anais do XXXII COBENGE (Campina Grande, 2005). Disponível em http://www.abenge.org.br/CobengeAnteriores/ 2005/artigos/BA-3-11560649534-1116538929533. pdf (acesso em 26/05/2014)

[16] J.A. Salvador, C. Constantino, N. Baldin e J.M. Póvoa, in: Anais do XXVII COBENGE (Natal, 1999), p. 993-1001. Disponível em http://www .abenge.org.br/ CobengeAnteriores/1999/st/t/t032.PDF (acesso em 26/05/2014)

[17] J.C. Morgado, Educ. Soc. 30, 37-62 (2009).

[18] J.F.Jr. Hair, R.E. Anderson, R.L. Tatham e W.C. Black, Análise Multivariada de Dados (Bookman, São Paulo, 2005), 593 p.

[19] P.F. Fávero, P. Belfiore, F.L. Silva e B.L. Chan, Análise de Dados: Modelagem Multivariada para Tomada de Decisão (Elsevier, Rio de Janeiro, 2009), 544 p. 